\title{
Efficiency Optimization of Pharmaceutical Wastewater Treatment by a Microwave-Assisted Fenton-Like Process Using Special Supported Catalysts
}

\author{
Xudong Qi' ${ }^{1,2 *}$, Zhihui $\mathbf{L i}^{2}$ \\ ${ }^{1}$ School of Environmental Science and Engineering, Tianjin University, Tianjin 300072, China \\ ${ }^{2}$ School of Energy and Environmental Engineering, Hebei University of Technology, Tianjin 300401, China
}

Received: 8 November 2015

Accepted: 30 January 2016

\begin{abstract}
The efficiency of a microwave-assisted Fenton-like process using special supported catalysts was evaluated using total organic carbon (TOC) removal from pharmaceutical wastewater. No acidification was required. The highest level of TOC removal efficiency from wastewater achieved was $65.88 \%$. Moreover, the maximum number of consecutive uses with high activity was four. Under optimal conditions, the influent value of $\mathrm{BOD}_{5} / \mathrm{COD}$ was 0.25 , and the effluent value of $\mathrm{BOD}_{5} / \mathrm{COD}$ was elevated to 0.40 . In addition, colour was completely removed. This efficiency was compared with the same MW-Fentonlike process using common supported catalysts, where the highest achieved TOC removal efficiency from wastewater was $39.25 \%$, the colour of the wastewater decreased from 50 to 20 , and the value of $\mathrm{BOD}_{5} /$ COD was elevated from 0.25 to 0.34 . The maximum number of consecutive high activity uses was two. This advanced performance was attributed to no presence of copper carbonate or cerium carbonate on the surface of special supported catalysts. The preparation method for these catalysts combined the merits of the isometric impregnation method with some new improvements. Its advantages include high-efficiency performance, short preparation time, low reagent usage (cupric nitrate $3.6 \mathrm{~g}$, cerium nitrate $1.2 \mathrm{~g}$, ammonia $1 \mathrm{~mL}$ ), and reusability. The properties of the catalyst with the most efficient performance were characterized by determining surface particle size, the relative amount of active components and promoters, and the stable crystal form of the active components.
\end{abstract}

Keywords: catalyst, Fenton-like, microwave, pharmaceutical wastewater, supported

\section{Introduction}

Microwave-assisted Fenton-like processes using special supported catalysts are one of the emerging types of advanced oxidation processes (Abbr. AOPs) that can

*e-mail: xudongqien@126.com generate hydroxyl radicals (i.e. $\mathrm{OH}$ ) through the catalysis of hydrogen peroxide $\left(\mathrm{H}_{2} \mathrm{O}_{2}\right)$ by solid catalysts [1].

Moreover, MW-Fenton-like processes using special supported catalysts can result in high efficiency with simple catalyst separation. When performed under normal atmospheric pressure and temperature they are also known as microwave-assisted catalytic oxidation processes [2-4]. 
Table 1. Characteristics of pharmaceutical wastewater filtered by quantitative filter.

\begin{tabular}{|c|c|c|c|c|c|c|c|}
\hline Index & $\begin{array}{c}\mathrm{COD} \\
(\mathrm{mg} / \mathrm{L})\end{array}$ & $\mathrm{BOD}_{5} / \mathrm{COD}$ & $\begin{array}{c}\mathrm{TOC} \\
(\mathrm{mg} / \mathrm{L})\end{array}$ & $\begin{array}{c}\mathrm{SS} \\
(\mathrm{mg} / \mathrm{L})\end{array}$ & $\mathrm{pH}$ & $\begin{array}{c}\mathrm{NH}_{4}^{+}-\mathrm{N} \\
(\mathrm{mg} / \mathrm{L})\end{array}$ & $\begin{array}{c}\text { colour } \\
(\mathrm{multiple})\end{array}$ \\
\hline Value & 1595 & 0.25 & 155.9 & 218 & 6.54 & 84 & 50 \\
\hline
\end{tabular}

The supported catalysts are mainly composed of activity components, along with catalyst promoters and supports [5]. Catalysts are prepared by impregnation [6-9] or, in the field of environmental catalysis, by precipitation methods [10-12].

In impregnation methods [13] the support is immersed in a solution containing activity components. The remaining liquid is removed when equilibrium is achieved, and the finished catalyst is finally obtained by calcination. Impregnation uses the shape of the support, and does not require catalyst moulding. In impregnation methods, the physical structures of the catalyst are determined by the catalyst support.

In precipitation methods, a crystal structure (or gel) of oxide, hydrous oxide or carbonate is obtained by dosing the precipitant in the metal salt solution with active components. Then the deposits are separated, cleaned, and calcinated to obtain the finished catalyst.

In this study, copper oxide and hydrous oxide (without copper carbonate), cerium oxide and hydrous oxide (without cerium carbonate), and granular activated carbon (GAC) from coal were used as activity components, catalyst promoters, and catalyst supports, respectively. Given the merits and drawbacks of impregnation methods, a preparation method for special supported catalysts was developed. This preparation method retained the merits of isometric impregnation [14-16] with some improvements.

In this study, the finished catalyst was prepared with high efficiency, uniform particle size, short preparation time, low reagent use, and good reusability. A significant improvement was observed in wastewater treatment. The efficiency of the MW-Fenton-like process using special supported catalysts was evaluated by total organic carbon (TOC) removal efficiency from pharmaceutical wastewater. The properties of the catalyst with the highest efficiency performance were characterised and evaluated.

\section{Materials and Methods}

\section{Wastewater and Materials}

Chemical synthetic pharmaceutical wastewater was collected from a pharmaceutical factory in Tianjin, China. The main products of the factory were GCLE (7-Phenglacetamido-3-chloromethyl-3-chloromethyl3-cephem-4-carboxylic acid p-methoxybenzyl ester, a cephalosporin intermediate) and riboflavin sodium phosphate, etc. Table 1 shows the characteristics of the pharmaceutical wastewater filtered using a quantitative filter. All reagents used in this study were analytically pure: cupric nitrate $\left(\mathrm{Cu}\left(\mathrm{NO}_{3}\right)_{2} \cdot 3 \mathrm{H}_{2} \mathrm{O}\right)$, cerium nitrate
$\left.\left(\mathrm{Ce}\left(\mathrm{NO}_{3}\right)_{3} \cdot 6 \mathrm{H}_{2} \mathrm{O}\right)\right)$, hydrogen peroxide $(30 \%)$, aqueous ammonia (22-25\%), etc.

\section{Experimental Methods}

\section{Catalyst Preparation and Characterisation Methods}

The special supported catalyst was prepared as follows. A total of $10 \mathrm{~g}$ of GAC (the minimum amount) was placed in a $250 \mathrm{~mL}$ beaker, 6.0 copper nitrate and $2.4 \mathrm{~g}$ cerium nitrate were added to the beaker, and $3.6 \mathrm{~mL}$ of distilled water was added dropwise until the water could not be completely absorbed. When the isometric impregnation method was performed, the amount of distilled water was fixed at $4 \mathrm{~mL} / 10 \mathrm{~g} \mathrm{GAC}$.

For optimization of the catalyst preparation method, quantified amounts of copper nitrate $(1.2,2.4,3.6,4.8$, $6.0 \mathrm{~g})$ and cerium nitrate $(0,0.6,1.2,1.8,2.4 \mathrm{~g})$ were added into the beaker with $4 \mathrm{~mL}$ of distilled water (Table 2 ). The mixture was subsequently stirred to dissolve the reagents. Aqueous ammonia $(1 \mathrm{~mL})$ and quantified GAC $(5,10,20,30,40 \mathrm{~g})$ were also added to the mixture.

The entire mixture was transferred to a pressure pan, which was heated at $120^{\circ} \mathrm{C}$ for $20 \mathrm{~min}$. High temperature water vapour was used as an inert gas. The hydrothermal reaction was a mutual reaction between ammonia and nitrate ions, which caused copper oxide and hydrous oxide (without copper carbonate) to play a more effective role as activity components in the inner or outer layers of the catalyst.

At the end of the reaction, the pressure pan was opened and the mixture was transferred to a crucible. Then the entire mixture in the crucible was transferred to a muffle furnace at a steady temperature $\left(200,300,400,500,600^{\circ} \mathrm{C}\right)$ for $1.5 \mathrm{~h}$. Finally, the finished catalyst was obtained. The properties of the special supported catalysts and GAC with the highest efficiency were characterized by scanning electron microscopy (SEM), energy dispersive X-ray (EDX) (Table 3), and X-ray diffraction (XRD).

Experiments for efficiency optimization of the MWFenton-like process using special supported catalysts were performed with no acidification in this study. Efficiency of the process was optimized by varying the amount of hydrogen peroxide; MW radiation power; irradiation time; the amounts of copper nitrate, cerium nitrate, and GAC; calcination temperature, etc. Amounts and intensity of factors are given in Table 4. Changes in efficiency were evaluated by TOC removal efficiency from pharmaceutical wastewater.

The wastewater treatment experiment was performed as follows. The finished catalyst and hydrogen peroxide 
Table 2. Surface element component contents of GAC.

\begin{tabular}{|c|c|c|}
\hline Element & $\begin{array}{c}\text { Weight percentage } \\
(\%)\end{array}$ & $\begin{array}{c}\text { Atomic percentage } \\
(\%)\end{array}$ \\
\hline $\mathrm{C}$ & 47.87 & 70.51 \\
\hline $\mathrm{O}$ & 6.18 & 6.83 \\
\hline $\mathrm{Mg}$ & 2.31 & 1.68 \\
\hline $\mathrm{Al}$ & 3.35 & 2.19 \\
\hline $\mathrm{Si}$ & 5.25 & 3.30 \\
\hline $\mathrm{Ca}$ & 35.06 & 15.48 \\
\hline Total & 100.00 & 100.00 \\
\hline
\end{tabular}

Table 3. Surface element component contents of the special supported catalyst.

\begin{tabular}{|c|c|c|}
\hline Element & $\begin{array}{c}\text { Weight percentage } \\
(\%)\end{array}$ & $\begin{array}{c}\text { Atomic percentage } \\
(\%)\end{array}$ \\
\hline $\mathrm{C}$ & 0.17 & 0.93 \\
\hline $\mathrm{O}$ & 3.78 & 15.38 \\
\hline $\mathrm{Ca}$ & 1.86 & 3.01 \\
\hline $\mathrm{Ce}$ & 28.06 & 13.02 \\
\hline $\mathrm{Cu}$ & 66.13 & 67.66 \\
\hline Total & 100.00 & 100.00 \\
\hline
\end{tabular}

were introduced into the wastewater and radiation was supplied using a MW oven without acidification at the beginning of the reaction. Hydroxyl radicals (OHs) were generated through catalysis of hydrogen peroxide by the finished catalysts.

\section{Analytical Methods}

In this study, chemical oxygen demand (COD) was measured using a COD rapid testing instrument (LianHua
Technology Company, Lanzhou, China). Biochemical oxygen demand $\left(\mathrm{BOD}_{5}\right)$ was determined using an IS6 BOD system (WTW Corporation, Germany), and TOC was analyzed using a TOC analyzer (SHIMADZU, Japan). $\mathrm{Cu}^{2+}$ ion concentration was measured using an atomic absorption spectrometer (HITACHI 180-80, Japan). Suspended solids (SS), $\mathrm{NH}_{4}{ }^{+} \mathrm{N}$, and colour were determined according to standard methods [17]. $\mathrm{pH}$ was measured using a $\mathrm{pH}$ meter (pH-3C; LeiCi, Shanghai, China). A Midea household MW oven was used with different MW radiation power levels, namely high $(700 \mathrm{~W})$, medium-high $(539 \mathrm{~W})$, medium $(385 \mathrm{~W})$, and medium-low $(281 \mathrm{~W})$.

\section{Results and Discussion}

\section{Effect of Hydrogen Peroxide Amount}

To investigate the effect of hydrogen peroxide on the efficiency of the process, five $1 \mathrm{~L}$ samples with the original concentration were prepared. Hydrogen peroxide was introduced at the proportion of $2.5,5.0,7.5,10$, and 25 $\mathrm{mL} / 250 \mathrm{~mL}$ wastewater. The finished catalyst was added to these samples, and the MW radiation power was set at medium-high $(539 \mathrm{~W})$, with a radiation time of $6 \mathrm{~min}$. Influent and effluent TOC were determined by the test methods shown in Figure 1a. When hydrogen peroxide was used at $2.5,5.0,7.5,10$, and $25 \mathrm{~mL} / 250 \mathrm{~mL}$, the TOC removal from pharmaceutical wastewater was $53.12 \%$, $61.45 \%, 65.79 \%, 68.86 \%$, and $70.94 \%$, respectively. Thus, based on the efficiency of wastewater treatment and minimization of reagent usage, the optimal hydrogen peroxide ratio was $7.5 \mathrm{~mL} / 250 \mathrm{~mL}$.

\section{Effect of MW Radiation Power}

We used MW radiation power levels of high $(700 \mathrm{~W})$, medium-high $(539 \mathrm{~W})$, medium $(385 \mathrm{~W})$, mediumlow $(281 \mathrm{~W})$, and none $(0 \mathrm{~W})$. Oxidation decomposition occurred in the Fenton-like process using the special

Table 4. Design of the activity optimization experiment on special supported catalysts.

\begin{tabular}{|c|c|c|c|c|c|c|c|}
\hline \multirow[b]{2}{*}{ Influencing factor } & \multicolumn{7}{|c|}{ Amount or intensity of each influencing factor } \\
\hline & $\begin{array}{c}\mathrm{H}_{2} \mathrm{O}_{2} \text { amount } \\
(\mathrm{mL})\end{array}$ & $\begin{array}{c}\text { MW radiation } \\
\text { power }(\mathrm{W})\end{array}$ & $\begin{array}{l}\text { Radiation } \\
\text { time (min) }\end{array}$ & $\begin{array}{l}\text { Copper } \\
\text { nitrate }(g)\end{array}$ & $\begin{array}{l}\text { Cerium } \\
\text { nitrate } \\
(\mathrm{g})\end{array}$ & GAC (g) & $\begin{array}{c}\text { Calcination } \\
\text { temperature } \\
\left({ }^{\circ} \mathrm{C}\right)\end{array}$ \\
\hline $\mathrm{H}_{2} \mathrm{O}_{2}$ & $2.5 \sim 25$ & 539 & 6 & 3.6 & 1.2 & 10 & 400 \\
\hline MW radiation power & 7.5 & $0 \sim 700$ & 6 & 3.6 & 1.2 & 10 & 400 \\
\hline Radiation time & 7.5 & 539 & $2 \sim 10$ & 3.6 & 1.2 & 10 & 400 \\
\hline Copper nitrate & 7.5 & 539 & 6 & $1.2 \sim 6.0$ & 1.2 & 10 & 400 \\
\hline Cerium nitrate & 7.5 & 539 & 6 & 3.6 & $0 \sim 2.4$ & 10 & 400 \\
\hline GAC & 7.5 & 539 & 6 & 3.6 & 1.2 & $5 \sim 40$ & 400 \\
\hline Calcination temperature & 7.5 & 539 & 6 & 3.6 & 1.2 & 10 & $200 \sim 600$ \\
\hline
\end{tabular}


supported catalysts. The water samples containing $7.5 \mathrm{~mL}$ of $\mathrm{H}_{2} \mathrm{O}_{2} / 250 \mathrm{~mL}$ wastewater and the finished catalyst were irradiated at five MW levels to optimize the MW-Fentonlike process. Influent and effluent TOC was determined using the test methods shown in Fig. 1b.

When the MW radiation power was high $(700 \mathrm{~W})$, medium-high (539 W), medium (385 W), mediumlow $(281 \mathrm{~W})$, and none $(0 \mathrm{~W})$, values of TOC removal from pharmaceutical wastewater were $62.93 \%, 68.97 \%$, $69.96 \%, 35.27 \%$, and $23.43 \%$, respectively. Thus, the optimal MW radiation power was medium-high (539 W). When the MW radiation power was increased to high $(700 \mathrm{~W})$, TOC removal efficiency from wastewater increased little, the reason being that high radiation power led to disabled decomposition of hydrogen peroxide.

\section{Effect of Radiation Time}

The MW-Fenton-like process with special supported catalysts was explored at radiation times of 2, 4, 6, 8, and $10 \mathrm{~min}$, respectively. Influent and effluent TOC was determined after the reaction had ended by the test methods shown in Fig. 1c. When the radiation time was $2,4,6,8$, and $10 \mathrm{~min}$, the TOC removal efficiency from pharmaceutical wastewater was $37.84 \%, 58.91 \%, 65.45 \%$, $65.68 \%$, and $65.73 \%$. Thus, the optimal radiation time was $6 \mathrm{~min}$. When the radiation time was increased from 6 to $10 \mathrm{~min}$, the TOC removal of wastewater did not increase, the reason being that hydrogen peroxide was completely decomposed at a radiation time of $6 \mathrm{~min}$.

\section{Effect of Copper Nitrate Amount}

Copper was the activity component of the catalysts for the Fenton-like process [18]. The amounts of copper nitrate were $1.2,2.4,3.6,4.8$, and $6.0 \mathrm{~g}$ (Table 2). The volume of wastewater, the amount of hydrogen peroxide, MW radiation power, and radiation time were $250 \mathrm{~mL}$, $7.5 \mathrm{~mL}, 539 \mathrm{~W}$, and $6 \mathrm{~min}$, respectively. Influent and effluent TOC was determined using the test methods shown in Fig. 1d. In the catalyst preparation, copper oxide and hydrous oxide (without copper carbonate) was generated by the reaction of copper nitrate and a small amount of ammonia on the surface of the GAC, and was employed as a special supported catalyst. This method has not been previously reported [19-22].

Fig. 1d shows that TOC removal efficiency gradually increased from $59.15 \%$ to $66.11 \%$ when the copper nitrate amount increased from $1.2 \mathrm{~g} / 10 \mathrm{~g}$ GAC to $3.6 \mathrm{~g} / 10 \mathrm{~g}$ GAC. This relatively large increase resulted because more copper oxide and hydrous oxide was produced, and therefore more hydroxyl radical was generated. When the copper nitrate amount increased from $3.6 \mathrm{~g} / 10 \mathrm{~g}$ GAC to $6.0 \mathrm{~g} / 10 \mathrm{~g} \mathrm{GAC}$, the increase in TOC removal was small (from $66.11 \%$ to $66.68 \%$ ). This result was attributed to an excess of copper oxide and hydrous oxide, resulting in the disabled decomposition of hydrogen peroxide. Thus, the optimal dosage of copper nitrate in catalyst preparation was $3.6 \mathrm{~g} / 10 \mathrm{~g}$ GAC. This low reagent usage was a characteristic of the process.

Leaching of copper was measured by atomic absorption spectrometry, and the value was calculated to be $0.089 \mathrm{~g} / 3.6 \mathrm{~g}$ (for copper nitrate).

\section{Effect of Cerium Nitrate Amount in the Catalyst Preparation}

Ce played the role of catalyst promoter [23]. The cerium nitrate amounts were $0,0.6,1.2,1.8$, and $2.4 \mathrm{~g}$. (Table 2). In the muffle furnace, cerium nitrate reacted with ammonia to generate cerium oxide and hydrous oxide (without cerium carbonate) on the surface of GAC. Five types of finished catalysts were obtained using different amounts of cerium nitrate. The volume of wastewater, the hydrogen peroxide amount, the MW power, and the MW radiation time were $250 \mathrm{~mL}, 7.5 \mathrm{~mL}, 539 \mathrm{~W}$, and $6 \mathrm{~min}$, respectively. Influent and effluent TOC was determined by the test methods shown in Fig. 1e.

As shown in Fig. 1e, TOC removal efficiency from wastewater increased from $60.89 \%$ to $69.75 \%$ when the cerium nitrate amount increased from $0 \mathrm{~g} / 10 \mathrm{~g}$ GAC to $1.2 \mathrm{~g} / 10 \mathrm{~g} \mathrm{GAC}$ - a relatively large increase. Literature about AOPs has for a long time focused on catalyst promoters $[24,25]$. Therefore, cerium oxide and hydrous oxide (without cerium carbonate) were used as promoters to cause copper oxide and hydrous oxide to play a role as activity components either at the inner or outer layers of the GAC, thereby improving the efficiency of the process by generating more hydroxyl radicals.

When the cerium nitrate amount was increased from $1.2 \mathrm{~g} / 10 \mathrm{~g}$ GAC to $2.4 \mathrm{~g} / 10 \mathrm{~g} \mathrm{GAC}$, there was a small decrease in TOC removal efficiency from $69.75 \%$ to $67.95 \%$. At higher amounts of cerium nitrate $(>1.2 \mathrm{~g} / 10 \mathrm{~g}$ GAC), cerium oxide (or hydrous oxide) and copper oxide (or hydrous oxide) competed with each other for loading on the catalyst support (GAC). Too much cerium nitrate led to lower loading of copper oxide (or hydrous oxide) on the catalyst support, reducing the efficiency of the process. Thus, the optimal ratio of cerium nitrate in catalyst preparation was $1.2 \mathrm{~g} / 10 \mathrm{~g} \mathrm{GAC}$.

\section{Effect of GAC Amount in the Catalyst Preparation}

GAC played the role of catalyst support, providing a reaction surface for generating hydroxyl radicals by the reaction of hydrogen peroxide and the finished catalyst. The GAC amounts used were 5, 10, 20, 30, and $40 \mathrm{~g}$. (Table 2). Five types of finished catalyst were obtained using different amounts of GAC. The volume of wastewater, the amount of hydrogen peroxide, MW power, and MW radiation time were $250 \mathrm{~mL}, 7.5 \mathrm{~mL}, 539$ $\mathrm{W}$, and $6 \mathrm{~min}$, respectively. Influent and effluent TOC was determined by the test methods shown in Fig. 1f.

Use of $5 \mathrm{~g}$ of GAC resulted in relatively low TOC removal efficiency from wastewater (62.30\%; Fig. 1f). This result was attributed to the small reaction surface between the catalyst and hydrogen peroxide. 
However, when the GAC amount was increased from $5 \mathrm{~g}$ to $10 \mathrm{~g}$, there was a large increase in TOC removal efficiency from wastewater (from $62.30 \%$ to $68.16 \%$ ). Further increases in the amount of GAC used (such as 20,30 , or $40 \mathrm{~g}$ ) would result in further increased TOC

a)

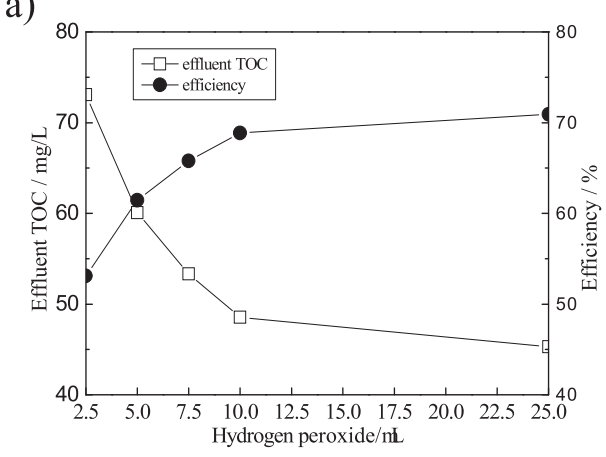

c)

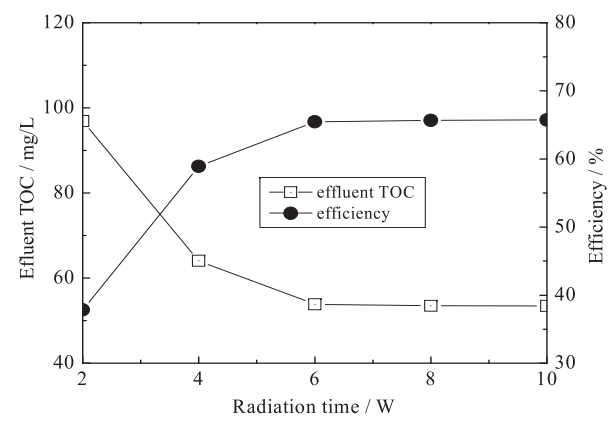

e)

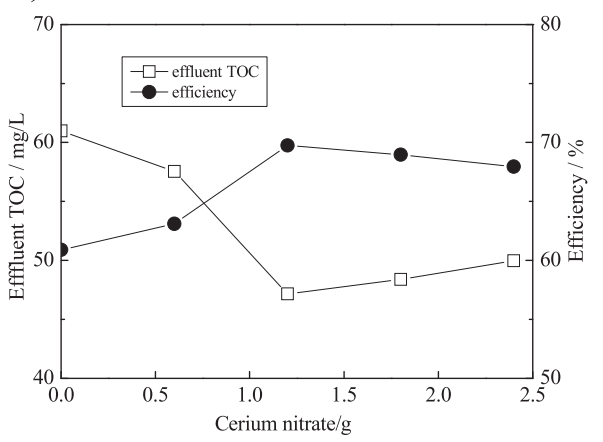

g)

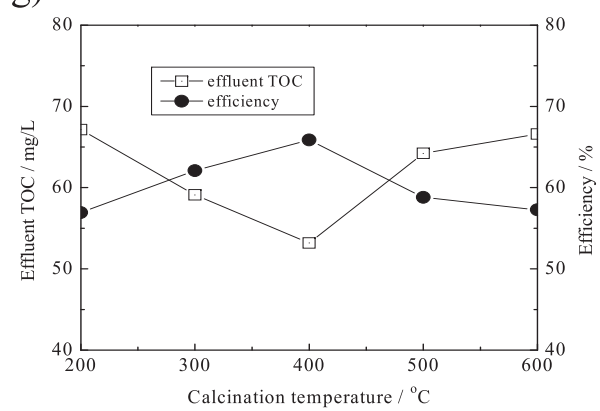

removal efficiency from wastewater because the reaction surface area of the finished catalysts would be increased accordingly. Compared amounts of all reagent usages with the surface of GAC, the optimal amount of GAC in the catalyst preparation was $10 \mathrm{~g}$. b)

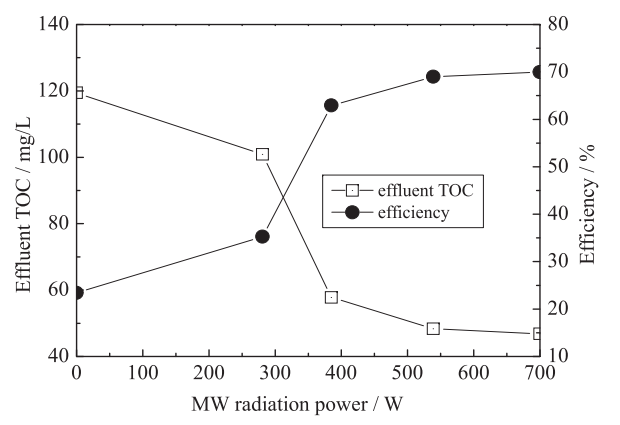

d)

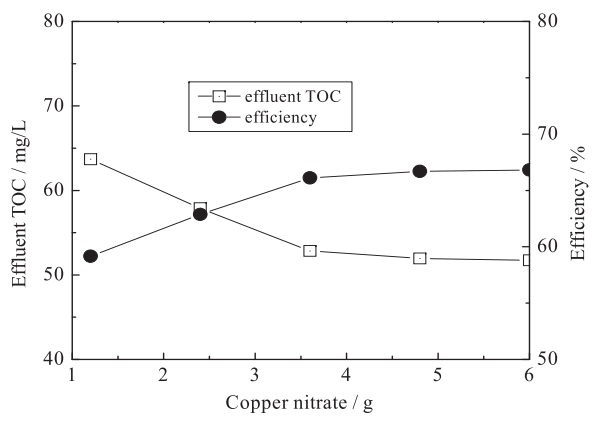

f)

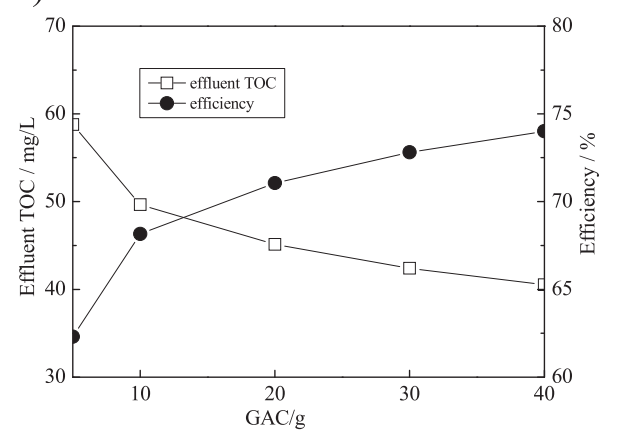

Fig. 1. Effects of factors a) hydrogen peroxide amount, b) MW radiation power, c) radiation time, d) copper nitrate amount, e) cerium nitrate amount, f) activated carbon amount, and g) calcination temperature on the efficiency of the MW-Fenton-like process using special supported catalysts $\left(\mathrm{TOC}_{0}=155.9 \mathrm{mg} / \mathrm{L}\right.$, no acidification $)$. 


\section{Effect of Calcination Temperatures in Catalyst Preparation}

The calcination temperatures were $200^{\circ} \mathrm{C}, 300^{\circ} \mathrm{C}$, $400^{\circ} \mathrm{C}, 500^{\circ} \mathrm{C}$, and $600^{\circ} \mathrm{C}$. The other preparation conditions are shown in Table 2. Five types of finished catalysts were obtained using different calcination temperatures. Influent and effluent TOC was determined by the test methods shown in Fig. 1g. The highest TOC removal efficiency of wastewater was obtained $(65.88 \%)$ with the catalyst prepared at a calcination temperature of $400^{\circ} \mathrm{C}$ (Fig. 1g). TOC removal efficiency of the wastewater with catalysts prepared at other calcination temperatures was lower. The temperature of calcination influenced the bonding force among copper oxide, cerium oxide (or hydrous oxide) and GAC. There are several reasons for these results. First, a very low temperature $\left(200^{\circ} \mathrm{C}\right)$ led to the low yield and poor adhesion ability of copper oxide and cerium oxide (or hydrous oxide) on the surface of the support. Second, very high temperatures $\left(500^{\circ} \mathrm{C}, 600^{\circ} \mathrm{C}\right)$ led to strong oxidation of GAC and was antagonistic to the generation and loading of copper oxide and cerium oxide (or hydrous oxide). Thus, the optimal calcination temperature in catalyst preparation was $400^{\circ} \mathrm{C}$.

\section{Change in $\mathrm{BOD}_{5} / \mathrm{COD}$ and Colour of the Wastewater under Optimal Conditions}

The MW-Fenton-like process using special supported catalysts was explored under predetermined optimal conditions. The volume of wastewater, hydrogen peroxide amount, MW radiation power, and MW radiation time were $250 \mathrm{~mL}, 7.5 \mathrm{~mL}, 539 \mathrm{~W}$, and $6 \mathrm{~min}$, respectively. The COD and $\mathrm{BOD}_{5}$ of influent and effluent under optimal conditions were determined by the test methods outlined in Materials and Methods.

The $\mathrm{BOD}_{5} / \mathrm{COD}$ value of the influent was 0.25 , and the $\mathrm{BOD}_{5} / \mathrm{COD}$ value of effluent was increased to 0.40 . Thus, the biodegradation of the wastewater was obviously

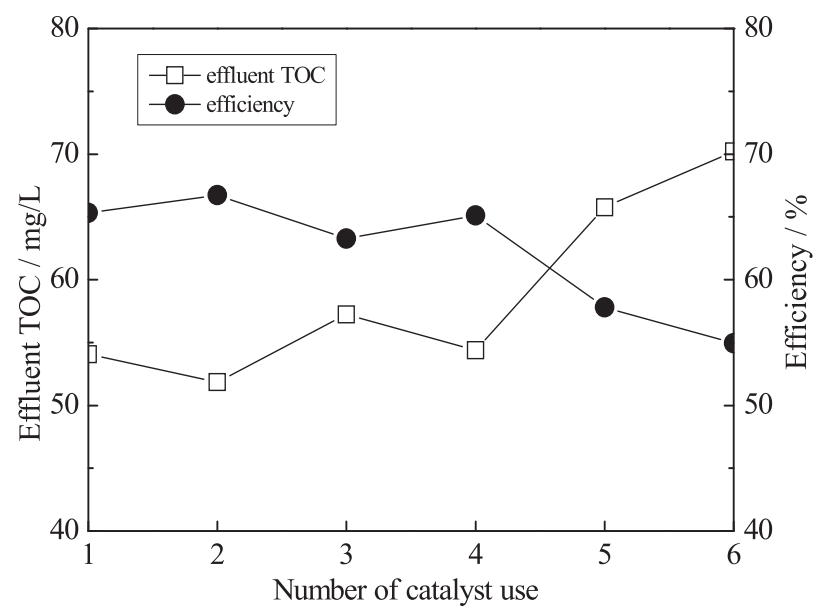

Fig. 2. Effects of the number of uses of the special supported catalyst on TOC removal efficiency $\left(\mathrm{TOC}_{0}=155.9 \mathrm{mg} / \mathrm{L}\right.$, no acidification). improved by the MW-Fenton-like process using special supported catalysts.

Moreover, the initial colour of the pharmaceutical wastewater was 50; after the treatment, the colour of the effluent was 0 .

\section{Catalyst Efficiency after Regeneration and Possibility for Multiple Use}

In the process of catalyst regeneration, catalysts were washed with distilled water after wastewater treatment [2628], transferred to a drying box at a constant temperature of $110^{\circ} \mathrm{C}$, and the drying time was $1.5 \mathrm{~h}$. The efficiency of the process was evaluated by TOC removal efficiency from wastewater, the experimental conditions were the same as above, and the possibility for multiple use of the catalyst with high-efficiency performance was checked. As shown in Fig. 2, the regenerated catalyst could be used with highly efficient performance four times. After being used four times, the catalyst starts to deactivate and should be discarded.

\section{Comparison with the MW-Fenton-like Process Using Common Supported Catalysts}

Common supported catalyst means a catalyst prepared using the ordinary impregnation method. $3.6 \mathrm{~g}$ of copper nitrate and $1.2 \mathrm{~g}$ of cerium nitrate were added into the beaker with $4 \mathrm{~mL}$ of distilled water. The mixture was subsequently stirred to dissolve the reagents. $10 \mathrm{~g}$ of GAC was also added to the mixture, which was transferred to a crucible and moved to a muffle furnace at a steady temperature of $400^{\circ} \mathrm{C}$ for $1.5 \mathrm{~h}$. Finally, the finished catalyst was obtained by ordinary impregnation method.

The MW-Fenton-like process using common supported catalysts was explored using radiation times of $2,4,6,8$, and $10 \mathrm{~min}$. The wastewater started to boil at 8 min. Influent and effluent TOC was determined by the test methods shown in Fig. 3.

At radiation times of 2, 4, 6, 8, and $10 \mathrm{~min}$, TOC removal efficiencies from wastewater were $21.47 \%$,

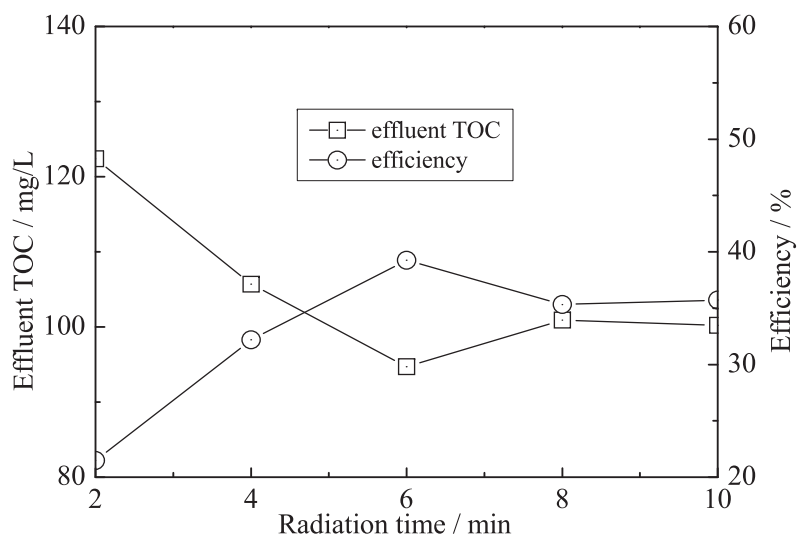

Fig. 3. Effects of radiation time on TOC removal efficiency in the experiment using common supported catalysts. 


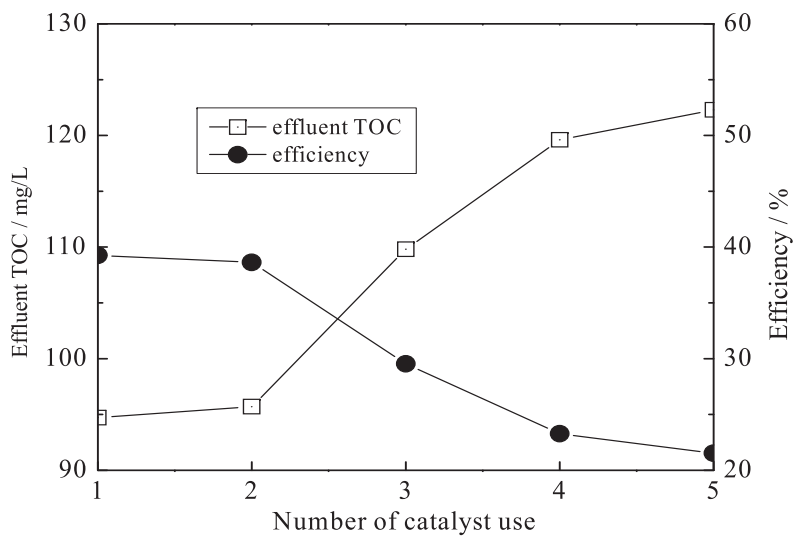

Fig. 4. Effect of the number of uses of common supported catalysts on TOC removal efficiency.

$32.18 \%, 39.25 \%, 35.31 \%$, and $35.72 \%$, respectively. Thus, the optimal radiation time was $6 \min (39.25 \%)$. Under these conditions, the coloration of the wastewater decreased from 50 to 20 , and the $\mathrm{BOD}_{5} / \mathrm{COD}$ value was

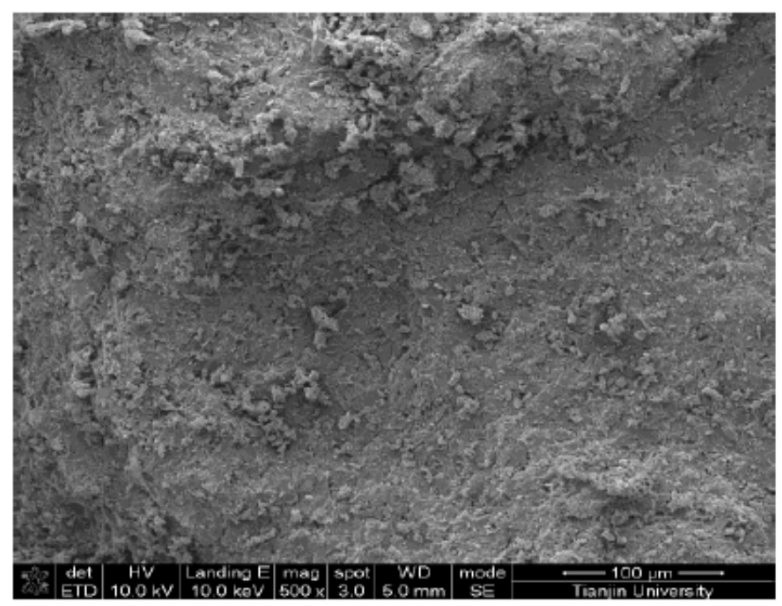

(a) $\mathrm{GAC} \times \mathbf{5 0 0}$

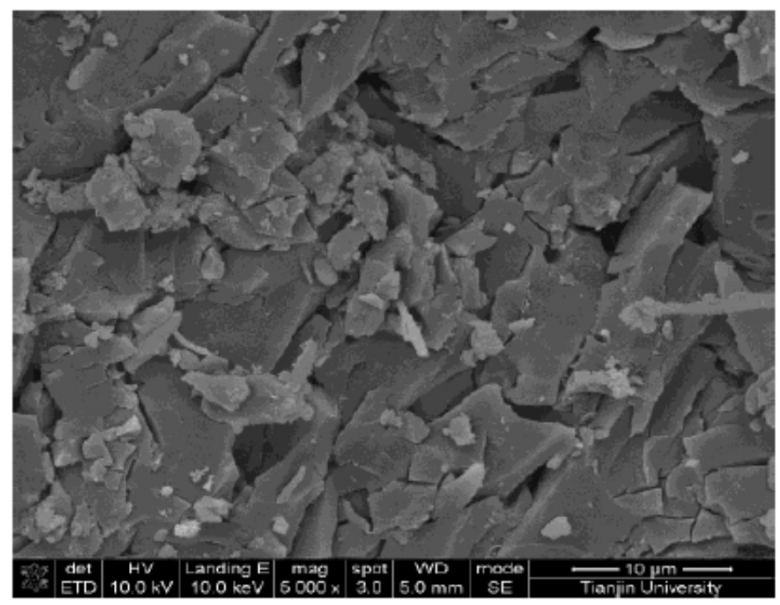

c) $\mathrm{GAC} \times 5000$ elevated from 0.25 to 0.34 . The efficiency of the MWFenton-like process using common supported catalysts was lower than the process using special supported catalysts. The special supported catalysts performed better because copper carbonate or cerium carbonate were not present on the catalyst surface.

The catalysts were washed with distilled water after wastewater treatment, and transferred to a drying box with a constant temperature of $110^{\circ} \mathrm{C}$. The drying time was $1.5 \mathrm{~h}$. The experimental conditions were invariant. As shown in Figure 4, the maximum number of uses of the catalysts with high performance was two. After being used two times, the catalyst started to deactivate.

Characterization of the Special Supported Catalysts with the Highest Performance Efficiency

The catalyst preparations combined the merits of the isometric impregnation method with some improvements, such as the hydrothermal reaction. The special supported catalysts also achieved better effects when used in wastewater treatment. The special supported catalysts

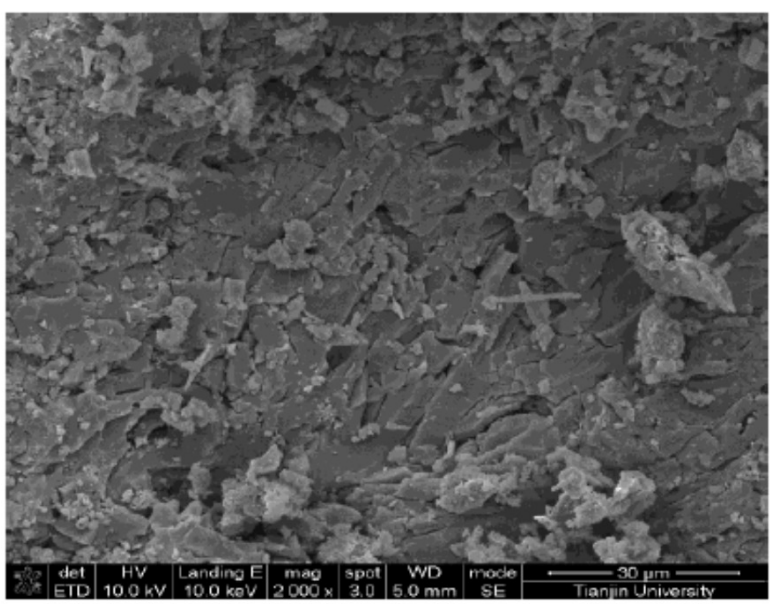

b) $\mathrm{GAC} \times 2000$

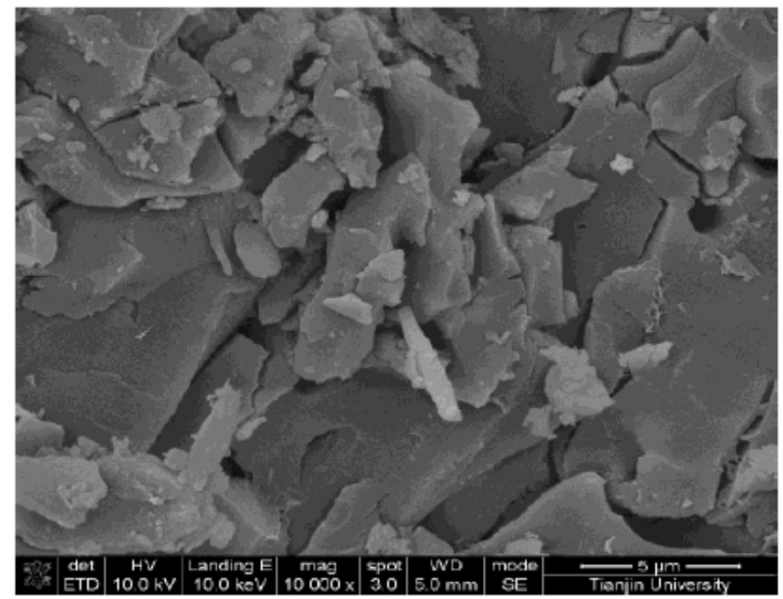

d) $\mathrm{GAC} \times 10000$

Fig. 5. SEM images of granular activated carbon (GAC). 
with the highest performance efficiency were produced at a calcination temperature of $400^{\circ} \mathrm{C}$. The catalyst preparations were characterized by SEM, EDX, and XRD [29-30].

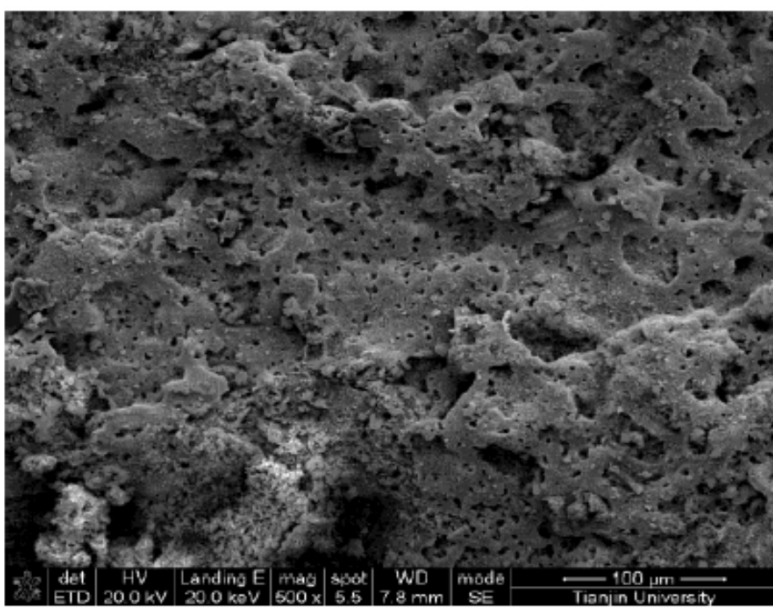

a) special $\times \mathbf{5 0 0}$

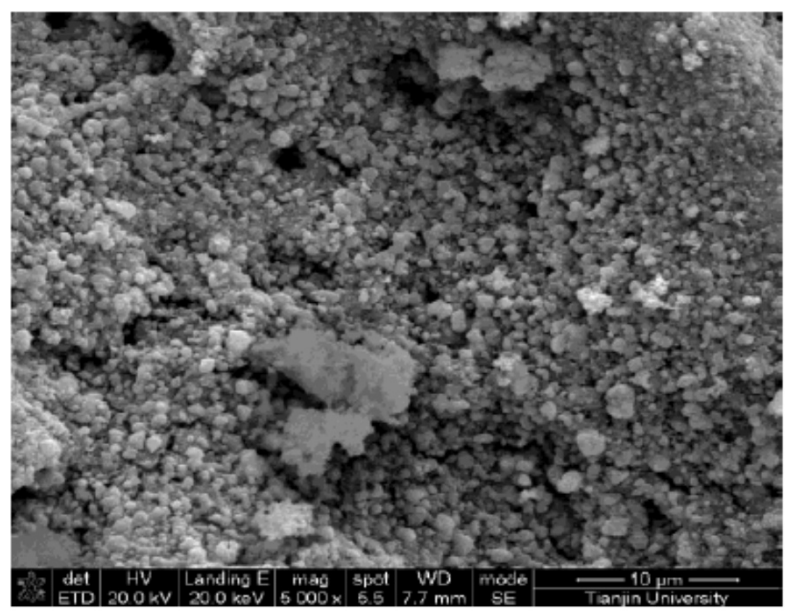

b) special $\times 5000$

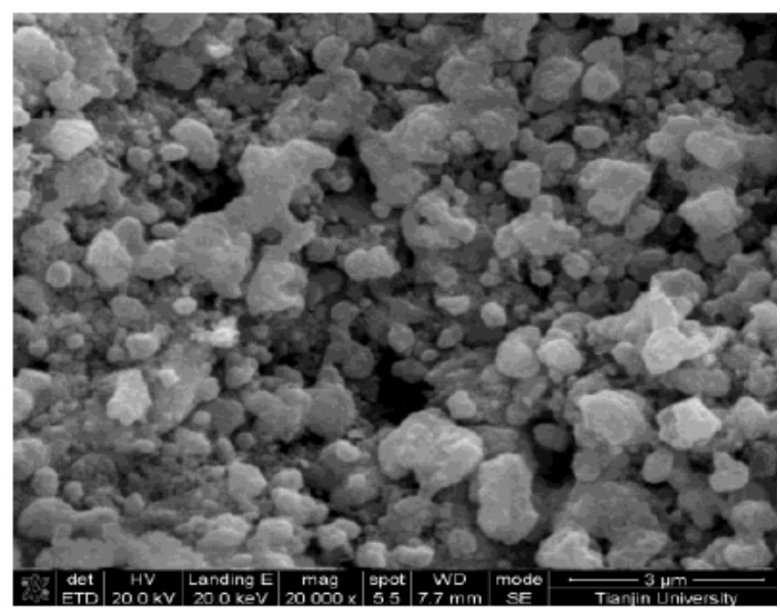

c) special $\times 20000$

Fig. 6. SEM images of the special supported catalysts with the highest efficiency performance.
SEM Analysis of Special Supported Catalysts

As shown in Figs 5 and 6, the surface structure of GAC (support) was stable and exhibited a uniform pore distribution. The particle size on the catalyst surface was also uniform. SEM analysis of the special supported catalysts indicated satisfactory catalyst distribution.

\section{EDX Tests on Special Supported Catalysts}

Surface element tests were performed using EDX (Table 3 and Table 4). GAC from coal was used as the catalyst support. Table 3 shows the relative amounts of $\mathrm{Ca}$, $\mathrm{Si}, \mathrm{Al}, \mathrm{Mg}, \mathrm{C}$, and $\mathrm{O}$, and Table 4 shows that the relative amounts of the activity components and promoters were $\mathrm{Cu}$ at $66.13 \%$ and $\mathrm{Ce}$ at $28.06 \%$. No copper carbonate or cerium carbonate was detected.

\section{XRD Tests on Special Supported Catalysts}

As shown in Fig. 7, copper oxide was the only crystal component in the special supported catalysts, cerium oxide was undersized and amorphous, and other crystal components detected were part of the GAC.

a)

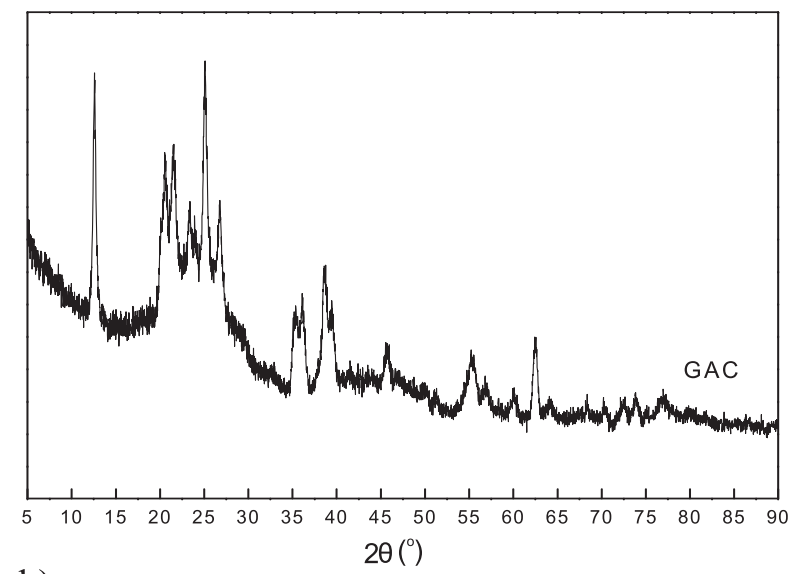

b)

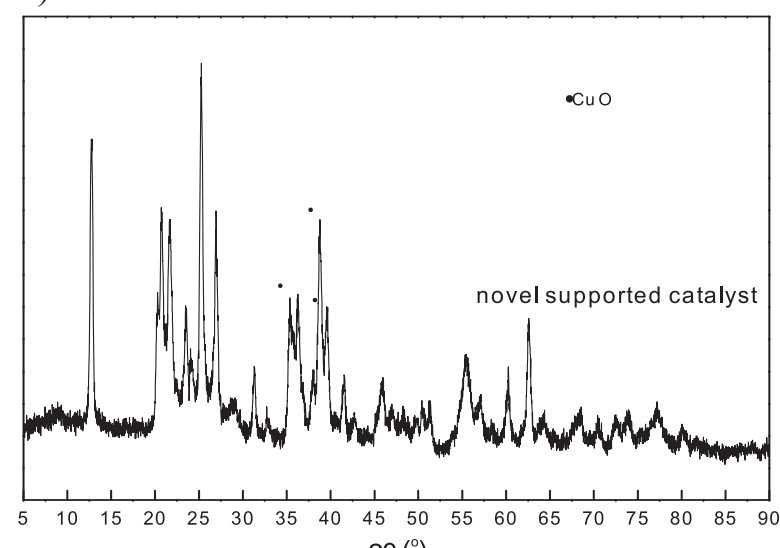

$2 \theta\left(^{\circ}\right)$

Fig. 7. XRD pattern of a) GAC and b) special supported catalysts with the highest efficiency performance. 


\section{Conclusions}

The efficiency of an MW-Fenton-like process using special supported catalysts was evaluated by TOC removal efficiency from wastewater. The highest TOC removal efficiency was $65.88 \%$ under optimal conditions without acidification. Moreover, the $\mathrm{BOD}_{5} / \mathrm{COD}$ value was elevated from 0.25 to 0.40 , colour was removed completely, and the maximum number of consecutive uses was four. By comparison, the MW-Fenton-like process using common supported catalysts (efficiency $=39.25 \%$ ) achieved a $\mathrm{BOD}_{5} / \mathrm{COD}$ increase from 0.25 to 0.34 , and a decrease in colour of the wastewater from 50 to 20 , and could be used for two times at most.

The properties of the catalysts with the highest efficiency performance were characterized. Particles sizes were uniform and the relative amounts of activity components and promoters were excellent (the copper and cerium percentages were $66.13 \%$ and $28.06 \%$, respectively). Copper oxide was the only crystal form, and no copper carbonate or cerium carbonate was detected.

In the catalyst preparation, copper oxide and hydrous oxide (without copper carbonate) was generated by copper nitrate and a small amount of ammonia, which was employed as the special supported catalyst. The high efficiency performance of the process was attributed to the lack of copper carbonate. Cerium oxide and hydrous oxide (without cerium carbonate) were used as promoters, causing the copper oxide and hydrous oxide to play the role of activity components either at the inner or outer layers of the GAC.

\section{Acknowledgements}

This work was financially supported by the Major National Water Pollution Control and Management of Science and Technology Special Topic (2008ZX07314001-02) and the National Science and Technology Support Program Topic (2012BAC13B05).

\section{References}

1. WANG N.N., WANG P. Study and application status of microwave in organic wastewater treatment - A review. Chem. Eng. J. 283, 193, 2016.

2. SUN Y., ZHANG Y.B., QUAN X. Treatment of petroleum refinery wastewater by microwave-assisted catalytic wet air oxidation under low temperature and low pressure. Sep. Purif. Technol. 62, 565, 2008.

3. ZHANG Y.B., QUAN X., CHEN S., ZHAO Y.Z., YANG F.L. Microwave assisted catalytic wet air oxidation of $\mathrm{H}$-acid in aqueous solution under the atmospheric pressure using activated carbon as catalyst. J. Hazard. Mater. 137, 534, 2006.

4. ATTA A.Y., JIBRIL B.Y., AL-WAHEIBI T.K., ALWAHEIBI Y.M. Microwave-enhanced catalytic degradation of 2- nitrophenol on alumina-supported copper oxides. Catal. Commun. 26, 112, 2012.

5. MARTINS R.C., AMARAL-SILVA N., QUINTA-
FERREIRA R.M. Ceria based solid catalysts for Fenton's depuration of phenolic wastewaters, biodegradability enhancement and toxicity removal. Appl. Catal. B 99, 135, 2010.

6. LIU X., KHINAST J.G., GLASSER B.J. A parametric investigation of impregnation and drying of supported catalysts. Chem. Eng. Sci. 63, 4517, 2008.

7. LI G.H., HU L.J., HILL J.M. Comparison of reducibility and stability of alumina-supported Ni catalysts prepared by impregnation and co-precipitation. Appl. Catal. A 301, 16, 2006.

8. SHU Y.Y., MURILLO L.E., BOSCO J.P., HUANG W., FRENKEL A.I., CHEN J.G. The effect of impregnation sequence on the hydrogenation activity and selectivity of supported Pt/Ni bimetallic catalysts. Appl. Catal. A 339, 169, 2008.

9. LEE S.J., GAVRIILIDIS A. Supported Au Catalysts for Low Temperature CO Oxidation Prepared by Impregnation. J. Catal. 206, 305, 2002.

10. HUANG Z.W., CUI F., XUE J.J., ZUO J.L., CHEN J., XIA C.G. $\mathrm{Cu} / \mathrm{SiO}_{2}$ catalysts prepared by homo- and heterogeneous deposition-precipitation methods, Texture, structure, and catalytic performance in the hydrogenolysis of glycerol to 1,2-propanediol. Catal. Today 183, 42, 2012.

11. CEN Y.Q., LI X.N., LIU H.Z. Preparation of copper-based catalysts for methanol synthesis by acid-alkali-based alternate precipitation method. Chin. J. Catal. 27, 210, 2006.

12. QIAN K., FANG J., HUANG W.X., HE B., JIANG Z.Q., MA Y.S., WEI S.Q. Understanding the deposition-precipitation process for the preparation of supported Au catalysts. J. Mol. Catal. A 320, 97, 2010.

13. ROMERO-SÁEZ M., DIVAKAR D., ARANZABAL A., GONZÁLEZ-VELASCO J.R., GONZÁLEZ-MARCOS J.A. Catalytic oxidation of trichloroethylene over Fe-ZSM-5: Influence of the preparation method on the iron species and the catalytic behavior. Appl. Catal. B 180, 210, 2016.

14. CHANG F.W., KUO W.Y., YANG H.C. Preparation of $\mathrm{Cr}_{2} \mathrm{O}_{3}$ promoted copper catalysts on rice husk ash by incipient wetness impregnation. Appl. Catal. A 288, 53, 2005.

15. CHANG F.W., KUO M.S., TSAY M.T., HSIEH M.C. Hydrogenation of $\mathrm{CO}_{2}$ over nickel catalysts on rice husk ashalumina prepared by incipient wetness impregnation. Appl. Catal. A 247, 309, 2003.

16. BOWKER M., NUHU A., SOARES J. High activity supported gold catalysts by incipient wetness impregnation. Catal. Today 122, 245, 2007.

17. AMERICAN PUBLIC HEALTH ASSOCIATION. Standard Methods for the Examination of Water and Wastewater $\left(18^{\text {th }}\right.$ ed): Washington, DC, USA, 1992.

18. WANG N.N., ZHENG T., ZHENG T., JIANG J.P., WANG P. $\mathrm{Cu}(\mathrm{II})-\mathrm{Fe}(\mathrm{II})-\mathrm{H}_{2} \mathrm{O}_{2}$ oxidative removal of 3-nitroaniline in water under microwave irradiation. Chem. Eng. J. 260, 386, 2015.

19. ATTA A.Y., JIBRIL B.Y., AL-WAHEIBI T.K. Microwaveenhanced catalytic degradation of 2-nitrophenol on aluminasupported copper oxides. Catal. Commun. 26, 112, 2012.

20. ZHANG L., YAN F., SHU M.M., LI Q., ZHAO Z.Y. Investigation of the degradation behaviour of Methamidophos under microwave irradiation. Desalination 247, 396, 2009.

21. ZHANG Y.B., QUAN X., CHEN S., ZHAO Y.Z., YANG F.L. Microwave assisted catalytic wet air oxidation of $\mathrm{H}$-acid in aqueous solution under the atmospheric pressure using activated carbon as catalyst. J. Hazard. Mater. 137, 534, 2006.

22. BI X.Y., WANG P., JIANG H., XU H.Y., SHI S.J., HUANG J.L. Treatment of phenol wastewater by microwave-induced 
$\mathrm{ClO}_{2}-\mathrm{CuO} / \mathrm{Al}_{2} \mathrm{O}_{3}$ catalytic oxidation process. J. Environ. Sci.-China 19, 1510, 2007.

23. GUO R.T., CHEN Q.L., DING H.L., WANG Q.S., PAN W.G., YANG N.Z., LU C.Z. Preparation and characterization of $\mathrm{CeOx} @ \mathrm{MnOx}$ core-shell structure catalyst for catalytic oxidation of NO. Catal. Commun. 69, 165, 2015.

24. BI X.Y., WANG P., JIAO C.Y., CAO H.L. Degradation of remazol golden yellow dye wastewater in microwave enhanced $\mathrm{ClO}_{2}$ catalytic oxidation process. J. Hazard. Mater. 168, 895, 2009.

25. NIE Y.L., ZHANG L.L., LI Y.Y., HU C. Enhanced Fentonlike degradation of refractory organic compounds by surface complex formation of $\mathrm{LaFeO}_{3}$ and $\mathrm{H}_{2} \mathrm{O}_{2}$. J. Hazard. Mater. 294, 195, 2015.

26. BOLDRINI D.E., TONETTO G.M., DAMIANI D.E. Experimental study of the deactivation of $\mathrm{Pd}$ on anodized aluminum monoliths during the partial hydrogenation of vegetable oil. Chem. Eng. J. 270, 378, 2015.

27. DIAZ E., MOHEDANO A.F., CASAS J.A., RODRIGUEZ J.J. Analysis of the deactivation of Pd, Pt and Rh on activated carbon catalysts in the hydrodechlorination of the MCPA herbicide, Appl. Catal. B 181, 429, 2016.

28. TORRES-MANCERA P., RAYO P., ANCHEYTA J., MARROQUÍN G., CENTENO G., ALONSO F. Characterization of spent and regenerated catalysts recovered from a residue hydrotreating bench-scale reactor. Fuel 149, 143, 2015.

29. DUAN H.T., LIU Y., YIN X.H., BAI J.F., QI J. Degradation of nitrobenzene by Fenton-like reaction in a $\mathrm{H}_{2} \mathrm{O}_{2} /$ schwertmannite system. Chem. Eng. J. 283, 873, 2016.

30. INCHAURRONDO N., FONT J., RAMOS C.P., HAURE P. Natural diatomites: Efficiency green catalyst for Fenton-like oxidation of Orange II. Appl. Catal. B: Environ. 181, 481, 2016. 